\title{
Variational Principle of Si Content in Cast Al-Si Alloy during Melting Process
}

\author{
Ao Xiaohui, Xing Shuming*, Li Shaoqian, \\ Zhang Jiahong \\ School of Mechanical, Electronic and control Engineering, \\ Beijing jiaotong University, \\ Beijing 100044, China \\ smxing@bjtu.edu.cn
}

\begin{abstract}
The influence of temperate and time on variational principle of Si content in A356 recycled scrap during melting process was investigated in this paper. The results indicated that the variations of $\mathrm{Si}$ content showed conic laws which decreased firstly then increased with the holding time. The maximum descent, the full change content and the change rate all increased and the burning time shortened with the melting temperature increasing in the low and high temperature stage respectively. By thermodynamic analysis, we learned the change rates of Si content were decided both by the oxidation reaction of [Si] and reduction reaction of $\mathrm{SiO} 2$ by $\mathrm{Al}$. The main factors affecting the redox reactions were $\mathrm{O} 2$ content, $\mathrm{SiO} 2$ content, melting temperature and so on. The reduction reaction of $\mathrm{SiO} 2$ played a major role in $\mathrm{Si}$ content with oxygen consumed and $\mathrm{SiO} 2$ produced lately.
\end{abstract}

Keywords-Si content, melting temperature, holding time, thermodynamics, dynamics

\section{INTRODUCTION}

In the cast aluminum-silicon alloy, the change of Si content has an important effect on the microstructure and properties of the alloy [1]. The Al-Si alloys with different Si contents were added with quantitative amounts of B and Ti were studied by $\mathrm{Y}$ Birol [2], found that the Si content was at least $4 \%$ in order to achieve a good refinement effect, and the Ti will be removed by Ti-Si compound when the Si content was more than 5\%. Wang et al. [3] considered the increase of Si content of Al-Si-Mg alloy can obviously improve the dynamic recrystallization of hot extruded alloy and improve the tensile strength and elongation. Santhi [4] found that the casting volume shrinkage of A356 and A413 decreased when the Si content increased. Wu Yuna [5] pointed out that the increase of $\mathrm{Si}$ content in hypoeutectic casting Al-Si alloy can not only improve the tensile strength of as-cast, but also can effectively improve the dynamic recrystallization capacity of hot-extruded. For A356 with standard composition range, WANG [6] argued the increase of Si content could improve the tensile strength, yield strength and hardness of the alloy, but the plasticity decreased. The high-Si content of A356 alloy was more sensitive to refinement treatment and the mechanical properties can be optimized by $\mathrm{T} 6$ treatment [7]. The effect of Si on the fluidity of the Aluminum alloy was studied [8] and it was shown that the increase of $\mathrm{Si}$ content of A356 with standard composition range was beneficial to the fluidity.

This work is supported by the International Science and Technology Cooperation Program of China (2014DFA53050).

\author{
Han Qingyou \\ Department of Mechanical Engineering Technology, \\ Purdue University, \\ Indiana, 47907, Amercia
}

In the smelting process of aluminum alloy, complex metallurgical reactions would lead to chemical composition change. According to the Gibbs free energy [9], the tendency of each element in the heat-resistant aluminum alloy to be oxidized was analyzed and the oxidized order was $\mathrm{Al}>\mathrm{V}>\mathrm{Si}>\mathrm{Fe}$. Because the Gibbs free energy of Mn oxidized is much higher than $\mathrm{Al}$ [10], Mn is difficult to be oxidized, but the addition of Mn could improve the oxidation activity of $\mathrm{Al}$, which led $\mathrm{Al}$ serious burning. Liu [11] found that the burning amount of strontium was greater in the A356.2 aluminum alloy smelting process than that in the low-pressure casting machine insulation furnace. Studies showed that the increase of $\mathrm{Mg}$ content can lead to a significant increase of smelting slag [12]. Si is the main alloying element of cast aluminum alloy. However, there are few reports on the variation of Si content in the smelting process of Al-Si alloy. In this paper, the effect of melting temperature and holding time on the Si content of A356 recycled scrap in smelting process was studied.

\section{EXPERIMENTAL}

The samples used in the experiments were produced by a SG-G10123-type crucible resistance furnace using A356 recycled scrap. Each furnace experiment kept one temperate from low to high in turn and a same time of 6 hours. The melting temperatures were set to $640^{\circ} \mathrm{C}, 660^{\circ} \mathrm{C}, 680^{\circ} \mathrm{C}, 700^{\circ} \mathrm{C}, 720^{\circ} \mathrm{C}$, $740^{\circ} \mathrm{C}, 760^{\circ} \mathrm{C}$, respectively and monitored continuously with a K-type thermocouples $( \pm 0.5 \%)$. Once the material was molten and reached the set temperature, a zero sample was taken, then by the time of $2 \mathrm{~h}, 3 \mathrm{~h}, 4 \mathrm{~h}, 5 \mathrm{~h}, 6 \mathrm{~h}$. All the samples were taken below the liquid surface of $50 \mathrm{~mm}$ and cast into the cylinder $\Phi 30 \mathrm{~mm} \times 45 \mathrm{~mm}$ using a split mold of refractory sleeve and copper chill block. Three chemical composition points in every samples were tested using ARL3460 Direct Reading Spectrometer. The Si content of each sample was recorded and the average value calculated was taken as the actual Si content.

\section{RESULTS}

The variational principle of Si content with the holding time in different melting temperatures were shown in Fig. 1. It could be seen that although there were differences in the change of Si content with the holding time under different melting temperatures, the whole trend showed decreasing firstly and then increasing. During the melting process, the maximum change of Si content was in the range of $0.1 \%-0.4 \%$ and was as high as $10 \%-40 \%$ to the A356 standard composition range of 
$6.5 \%-7.5 \%$. Considering the maximum changes of Si content at different temperatures, it was not the higher the melting temperature, the greater the change amount, but the amount of change at $640^{\circ} \mathrm{C}$ was the largest, followed by $700^{\circ} \mathrm{C}, 740^{\circ} \mathrm{C}$, $760^{\circ} \mathrm{C}, 680^{\circ} \mathrm{C}, 720^{\circ} \mathrm{C}$, the changes of $\mathrm{Si}$ content was less than $0.1 \%$ at $660^{\circ} \mathrm{C}$.
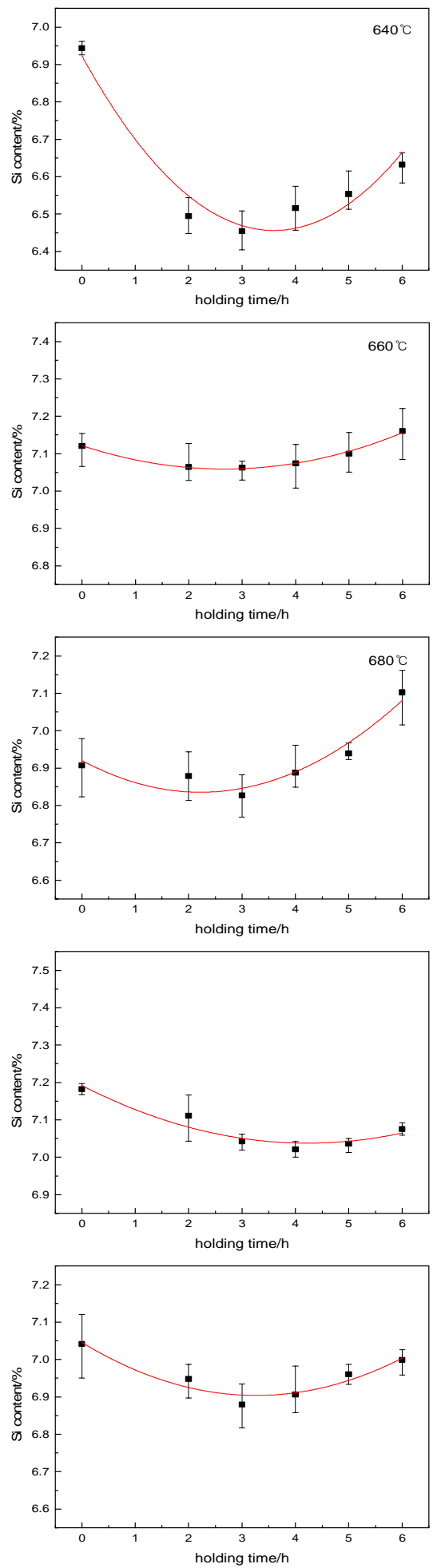
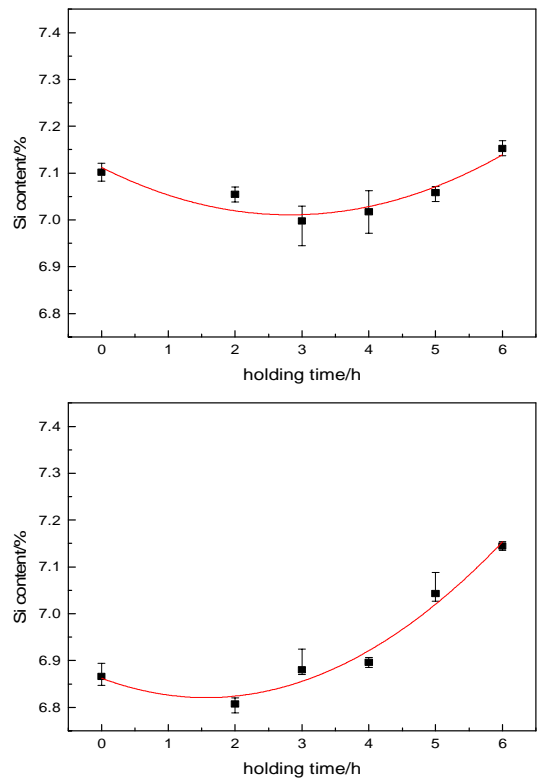

Fig. 1. Change laws of Si content with holding time.

Use the (1) to fit the variational principle of Si content with holding time and the fit coefficient and fit optimization were shown in Table I.

$$
Y_{S \mathrm{i}}=a t^{2}+b t+c
$$

where, $Y_{S i}$ is the Si content, \%; $t$ is the holding time, h.

TABLE I. FIT COEFFICIENT AND FIT OPTIMIZATION OF VARIATIONAL PRINCIPLE OF SI CONTENT WITH HOLDING TIME.

\begin{tabular}{ccccc}
\hline Temperate $/{ }^{\circ} \mathrm{C}$ & $a$ & $b$ & $c$ & $R^{2}$ \\
\hline 640 & 0.038 & -0.274 & 6.941 & 0.974 \\
660 & 0.009 & -0.051 & 7.123 & 0.972 \\
680 & 0.017 & -0.076 & 6.920 & 0.868 \\
700 & 0.008 & -0.073 & 7.192 & 0.858 \\
720 & 0.013 & -0.087 & 7.045 & 0.858 \\
740 & 0.013 & -0.072 & 7.112 & 0.794 \\
760 & 0.017 & -0.061 & 6.870 & 0.850 \\
\hline
\end{tabular}

The horizontal and vertical coordinates of extreme point of Si content change curves were defined as the burning time $t_{A}$ and the maximum descent $\triangle A$. The laws of $\Delta A$ and the full change content $\Delta B$ with melting temperature were shown in Fig. 2(a), which showed the maximum decrease of Si content was $0.49 \%$ at $640^{\circ} \mathrm{C}$ and others maintained around $0.1 \%$ at $660^{\circ} \mathrm{C}-760^{\circ} \mathrm{C}$. The laws of burning time $t_{A}$ with melting temperature was shown in Fig. 2(b), which showed the burning time $t_{A}$ both shortened gradually in the low temperature stage of $640^{\circ} \mathrm{C}-680^{\circ} \mathrm{C}$ and the high stage of $700^{\circ} \mathrm{C}-760^{\circ} \mathrm{C}$ respectively. 


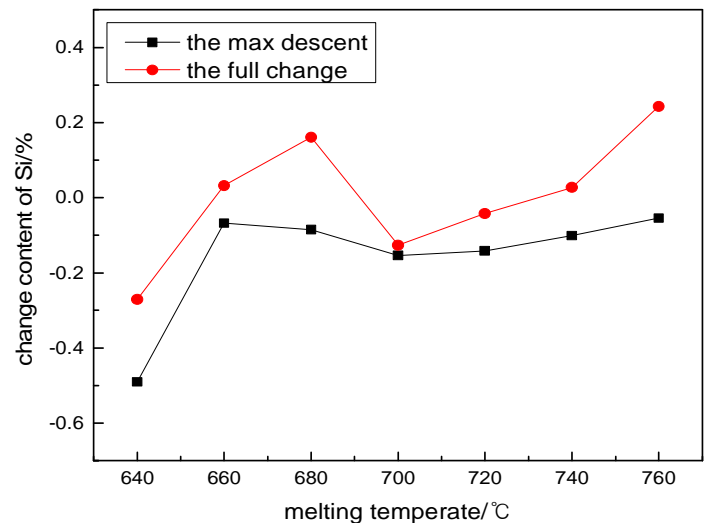

(a)

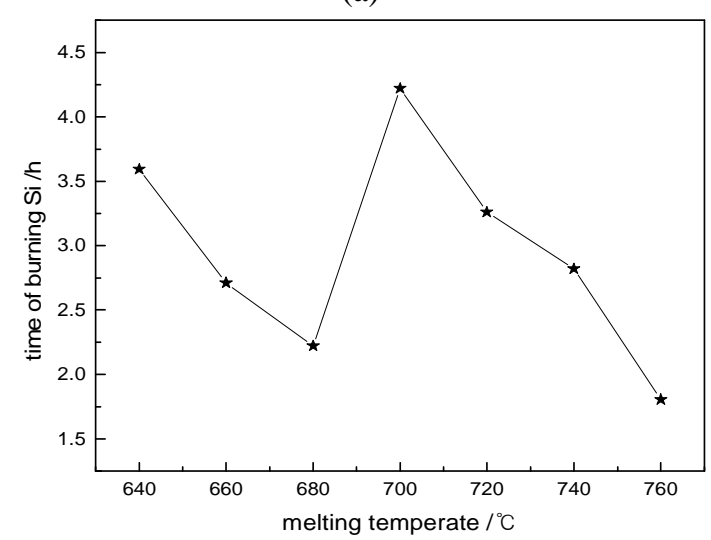

(b)

Fig. 2. Characteristic parameters of fitting curves of Si content.

Fig. 3 showed the change laws of Si content change rate with melting time in different melting temperate. At the low temperature (Fig. 4a), the change rate of Si content was higher at $640^{\circ} \mathrm{C}$ than other temperatures. When the melting temperature was improved to $660^{\circ} \mathrm{C}$, the change rate got slower and the $\mathrm{Si}$ content changed a little during the holding time. When the melting temperature was improved to $680^{\circ} \mathrm{C}$, the change rate was accelerated again, but slower than $640^{\circ} \mathrm{C}$. During the high temperature stage $\left(700^{\circ} \mathrm{C}-760^{\circ} \mathrm{C}\right)$, the change rates of $\mathrm{Si}$ content were accelerated with the temperature improved and the time reach to the minimum $\mathrm{Si}$ content was shortened, from $4.2 \mathrm{~h}$ at $700^{\circ} \mathrm{C}$ to $1.8 \mathrm{~h}$ at $760^{\circ} \mathrm{C}$

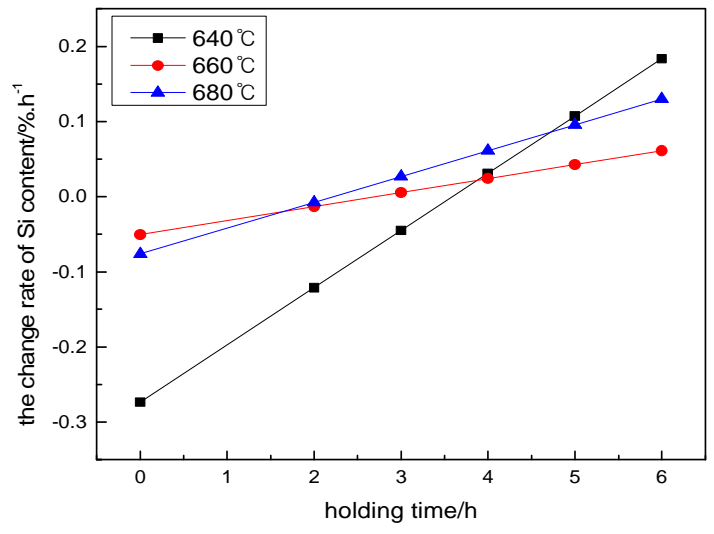

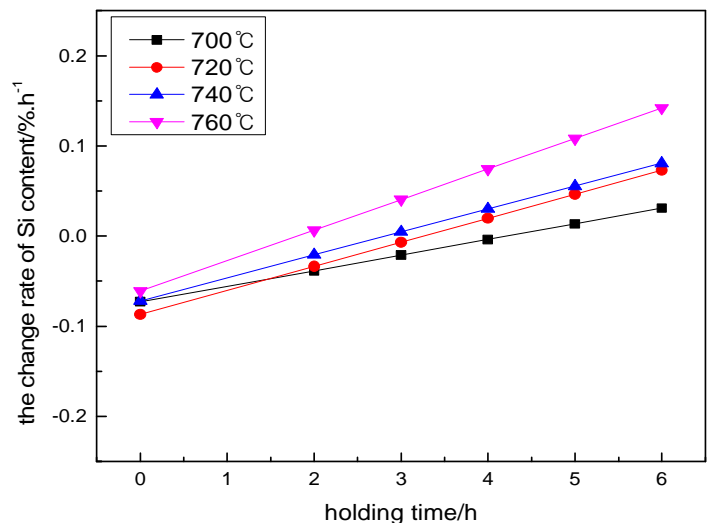

Fig. 3. Change laws of Si content change rate with holding time.

\section{ANALYSIS AND DISCUSSION}

During the aluminum smelting process, the reactions between $\mathrm{Si}-\mathrm{Al}-\mathrm{O}-\mathrm{SiO}_{2}$ were shown in (2)-(6). All the standard Gibbs free energy changes $(\mathrm{J} / \mathrm{mol})$ increased with temperature except $\mathrm{Si}$ dissolved reaction. However at the experimental temperature they were all less than zero, which explained all reactions could occur. The elemental activity could be insteaded by mass fraction and the slight change in mass fraction has little effect on free energy in this paper. Therefore take $a[\mathrm{Al}]=\omega[\mathrm{Al}]=0.92, a[\mathrm{Si}]=\omega[\mathrm{Si}]=0.07$.

$$
2 \mathrm{Al}(\mathrm{l})+\frac{3}{2} \mathrm{O}_{2}(\mathrm{~g})=\mathrm{Al}_{2} \mathrm{O}_{3}(\mathrm{~s}) ; \Delta G_{\mathrm{Al}_{2} \mathrm{O}_{3}}^{\theta}=-1682900+323.24 T
$$

$$
\begin{gathered}
\mathrm{Si}(\mathrm{s})+\mathrm{O}_{2}(\mathrm{~g})=\mathrm{SiO}_{2}(\mathrm{~s}) ; \Delta G_{\mathrm{SiO}_{2}}^{\theta}=-907100+175.73 T \\
\mathrm{Si}(\mathrm{s})=[\mathrm{Si}] ; \Delta G_{[\mathrm{Si}]}^{\theta}=-131500-17.61 T \\
{[\mathrm{Si}]+\mathrm{O}_{2}(\mathrm{~g})=\mathrm{SiO}_{2}(\mathrm{~s}) ;} \\
\Delta G_{\mathrm{SiO}_{2}}=-775600+193.34 T+R T \ln \frac{1}{0.07 *\left(P_{O_{2}} / P^{\theta}\right)}
\end{gathered}
$$

$$
\begin{gathered}
\left.\mathrm{SiO}_{2}(\mathrm{~s})+\frac{4}{3} \mathrm{Al}(\mathrm{l})=[\mathrm{Si}]+\frac{2}{3} \mathrm{Al}_{2} \mathrm{O}_{3} \mathrm{~s}\right) \\
\Delta G_{[\mathrm{Si}]}=-346333+32.15 T+R \ln \frac{0.07}{0.92^{4 / 3}}=-346333+10.91 T
\end{gathered}
$$

In the early melting, because the oxide film on the melt surface was not complete, the oxygen partial pressure of alloy liquid was large, (2)-(5) occurred, so [Si] was oxidized resulting in $\mathrm{Si}$ content decreased. As aluminum was continually oxidized to form oxide film and oxygen consumed [13], the growth rate of the oxide layer was accelerated and the oxygen partial pressure of melt gradually decreased, the ability of [Si] oxidized was weakened, so the rate of Si burning slowed down gradually. Because the density of $\mathrm{SiO}_{2}$ was slightly larger than that of $\mathrm{Al}$, the oxidized $\mathrm{SiO}_{2}$ was dispersed in the melt and sank slowly with holding time. $\mathrm{SiO}_{2}$ was reduced to [Si] by (6), when it 
increased to a certain amount. The oxidized $\mathrm{SiO}_{2}$ slowly sank to the bottom of the melt, the closer to the bottom of the melt, the greater the Si concentration. Therefore, as Si was oxidized to $\mathrm{SiO}_{2}$ and slowly sank, the $\mathrm{Si}$ concentration in the upper layer of the melt gradually decreased in the early and $\mathrm{Si}$ concentration gradually increased with the melt decreasing after samplings.

\section{SUMMARY}

(1) The change laws of Si content with the holding time show quadratic curves at different melting temperatures. The maximum descent $\Delta \mathrm{A}$, the full change content $\Delta \mathrm{B}$ and the change rate all increase and the burning time $t_{A}$ shorten with the melting temperature increasing. Under the experimental conditions, the maximum change of Si content is less than $0.5 \%$.

(2) The change trend of Si content is mainly determined by the rate of $\mathrm{Si}$ oxidized and the $\mathrm{SiO}_{2}$ reduced by aluminum. The factors influencing the rate of the redox reactions are oxygen content, $\mathrm{SiO}_{2}$ content, melting temperature and so on. The change rate of silicon content increases linearly with the holding time.

\section{REFERENCES}

[1] C.W. Chien, S.L. Lee, J.C. Lin and M.T. Jahn, "Effects of Si P size and volume fraction on properties of Al/Sip composites". Mater. Let. vol. 334, pp. 4-5, 2002.

[2] Y. Birol, "Effect of silicon content in grain refining hypoeutectic Al-Si foundry alloys with boron and titanium additions". Mater. Sci. Tech. vol. 28, pp. 385-389, 2012.

[3] Y.J. Wang, H.C. Liao, Y.N. Wu and Y. Jian, "Effect of Si content on microstructure and mechanical properties of Al-Si-Mg alloys". Mater. Des. vol. 53, pp. 634-638, 2014.

[4] S. Santhi, S.B. Sakri, H.R. Dharwada and S. Sundarrajan, Influence of silicon content on the volume deficit characteristic of cast Al-Si alloys. Mater. Res. Soc. vol. 28, pp. 3355-3366, 2013.

[5] Y.N. Wu, H.C. Liao, J. Yang and K.X. Zhou, "Effect of Si Content on Dynamic Recrystallization of $\mathrm{Al}-\mathrm{Si}-\mathrm{Mg}$ Alloys During Hot Extrusion". J. Mater. Sci. Tech. vol. 30, pp. 1271-1277, 2014.

[6] C.Q. Wang, Y.T. Zhao, S.L. Zhang, G. Chen and H.J. Yang, "Effects of Si and $\mathrm{Mg}$ Content and Alloying Elements on Mechanical Properties of A356 Alloy". Special Cast. Nonferr. Alloy. vol. 30, pp. 88-93, 2010.

[7] Y.H. Dai, J.X. Chen, X.X. Chu, "Influence of Si and Mg content on the performance of A356 Al alloy wheel". Foundry. vol. 63, pp. 257-261, 2014.

[8] H.R. Qi, G. Yang and Q.N. Shi, "Effect of Si and Mg on A356 alloy fluidity performance.Light Alloy Fabricat". Tech. vol. 35, pp. 19-23, 2007.

[9] D.Q. Tan and W.X. Li, "Physics-chemical Reaction during Melting Process of the Heat resistant Al-Fe-V-Si Alloy". Foundry. vol. 52, pp 675-678, 2003.

[10] S.C. Wilson, K. Anne, T.A. Engh and T. Gabriella, "Oxidation of manganese-containing aluminum alloys studied by SEM". Mater. Sci. Forum. vol. 794-796, pp. 1095-1100, 2014.

[11] H.L. Liu, "Sr Burning loss in A356.2 Aluminum Alloy in Melting Process". Special Cast. Nonferr. Alloy. vol. 31, pp. 540-541, 2011.

[12] I.I.I. Clark and A. John, Melt down dross on magnesium containing aluminum alloys. TMS 135th Annual Meeting. 2006, pp. 783-787.

[13] F.J. Liu, M.C. Zhang, J.X. Dong and Y.W. Zhang, "High temperature oxidation behavior of FGH95 alloy”. J. Univ. Sci. Tech. Beijing. vol. 29, pp. 704-707, 2007. 